\title{
THE INTEGRATION OF THE MULTI-TEMPORAL CONSERVATION WORKS AND NON-INVASIVE MEASUREMENTS
}

\author{
J. Markiewicz ${ }^{1 *}$, K. Górecka ${ }^{2}$, D. Zawieska ${ }^{1}$, M. Zieliński ${ }^{3}$, S. Łapiński ${ }^{1,}{ }^{1}$. Kot $^{4}$ \\ ${ }^{1}$ Faculty of Geodesy and Cartography, Warsaw University of Technology, Pl. Politechniki 1, 00-661 Warsaw, Poland, \\ (slawomir.lapinski , jakub.markiewicz, dorota.zawieska)@pw.edu.pl \\ ${ }^{2}$ Academy of Fine Arts in Warsaw, Faculty of Conservation and Restoration of Works of Art, katarzyna.gorecka@ cybis.asp.waw.pl \\ ${ }^{3}$ Documentation and Digitalization Department, Museum of King Jan III's Palace at Wilanów, \\ ul. Stanisława Kostki Potockiego 10/16, 02-958, Warsaw, Poland, mzielinski@ muzeum-wilanow.pl \\ ${ }^{4}$ Built Environment and Sustainable Technologies (BEST) Research Institute, Liverpool John Moores University, L3 3AF, \\ Liverpool, United Kingdom-P.Kot@ljmu.ac.uk
}

\section{Commission II}

KEY WORDS: Conservation works, multi-temporal data, data integration, SfM/MVS, TLS

\begin{abstract}
:
Heritage sites are affected by many factors that cause degradation and decay over time, such as soil deformation, changes in weather conditions, or excess moisture, which can cause damages to historical sites. For this reason, restoration works are planned and carried out to preserve the object's existing condition, renovate and repair the damaged parts, or restore the original condition of the object. The Rescue Project was undertaken in the Blessed Ladislas' chapel in St. Anna's Church in Warsaw, Poland. The main goal of the planned work was to restore the original rococo character of the dome paintings. The aim of this article was to present the integration of the multi-temporal conservation work and non-invasive measurements for changes analysis during conservation works. For this purpose, point clouds acquired with a Z+F 5006h ground-based scanner and images captured via Structure-from-Motion and MultiView Stereo method implemented in Agisoft Metashape software were used. The proposed conservation analysis method was a multi-stage process that involved: (1) automatic data integration using a feature-based approach based on 2D detectors and point clouds converted to spherical images, (2) generalisation and harmonisation of source data, and (3) analysis of deviations between point clouds. Having registered point clouds with each other, it was possible to analyse changes that occurred during conservation work. Calculated distances between both point clouds show the localisation of cracks and damages and enable measure of the size and depth of crevices on the dome wall.
\end{abstract}

\section{INTRODUCTION}

Nowadays, cultural heritage objects are exposed to different factors that cause their deterioration and degradation over time due to human activities and environmental factors (Stylianidis, 2019). For those reasons, it is necessary to perform rescue conservations works that allow for keeping cultural heritage objects and sites in good shape and condition for future generations.

In 2017, The Rescue Project was undertaken in the Blessed Ladislas' chapel in St. Anna's Church in Warsaw (Poland). The chapel, due to its spatial disposition - location from the escarpment side at the north wall of the church nave, belongs to the most endangered architectural fragments.

The chapel walls on the east-west axis have been cracked several times in the past due to the instability of the church foundation. A serious structural rupture fragmented the stone base of the lantern. Its loose elements threatened the safety of the faithful and visitors. Therefore, in the early XX-th century, its construction was tied with an iron clamp. In the dome, the cracks ran along the north-east direction according to the movement of the slope. In the southern part of the bowl at 1/3 of its height, the upper part of the plaster was cracked and detached from the brick support. The chapel walls were repaired several times so that the next putties and retouching are overlapped in many places.

The mural paintings of the chapel were renewed at the beginning of the XX-th century by painters, who "in memory" scratched their names on the dome walls. They totally repainted the original XVIII-th century composition, probably using tempera and oil binder. After II World War, the over-paintings were taken out with soda lye compresses. Unfortunately, the original Żebrowski's polychrome was also destroyed during that treatment. In many parts, the painting was lost. In the 70's of the XX-th century, the damaged paintings were restored, and missing elements were reconstructed, but the character of the ancient painting was completely changed.

There are traces of past injections and anchors all over the dome's surface. Old putties were made of gypsum and cement. Some of them covered the original layers. The XVIII-th century plasters had weakened adhesion to the support and poor cohesion. The surface of the painting was very dirty, the colour of the old retouches was changed.

Preserving the monument requires immediate constructional works and complete conservation and restoration treatment. The main goal of the planned work was to restore the original rococo character of the dome paintings. The project included constructional work at the stone base of the dome lantern (by introducing a new anchoring system). The damaged elements of the brick wall were consolidated, the detached fragments of the mortar were glued to the brick support, the inter-plaster dissection was consolidated, and the surface of the painting was cleaned from layers of dirt and salt. Old plaster repairs, retouching, and repainting were removed. Cracks and losses of the plaster layers were filled with putties. The preserved fragments of the paintings were restored. Missing elements of the painting composition were retouched and reconstructed. An analysis of the paintings was carried out based on art-historical research allowed for a reinterpretation of the meaning of the entire scene. In the chapel dome, there is an extensive scene of the procession of Polish saints and holy figures, led by Blessed Ladislaus from Gielniów and including Saint Mary at the moment of the Assumption, accompanied by the Holy Trinity: Christ, God the Father, and the Holy Spirit (presented as a dove 
on the ceiling lantern). The scene has a Latin inscription in the band: REGINA IN CORONA SANCTORUM REGNUM POLONIAE, which translates as Queen in the crown of saints of the Kingdom of Poland.

Therefore, this article aims to present the integration of the multi-temporal conservation works and non-invasive measurements based on the case study of St. Anna's Church in Warsaw.

\section{RELATED WORKS}

Architectural monuments such as buildings and small architecture such as garden sculptures, decorative vases, monuments, roadside statues or free-standing columns and obelisks are affected by degradation processes. The degradation rate depends on used materials' characteristics, object's age, and some random events. Physical phenomena often cause damage (e.g., deformations and displacement of a ground where the building is located or changes in hydrographic condition and vibrations). This might contribute to scratches, cracks, disconnections, crushing, leanings, and moisture which significantly affect the building structural health behaviour (Clim et al., 2017; ICOMOS, 2003).

To monitor the gradual deterioration of antique buildings and their decorative parts such as frescoes, wall paintings, etc., different measurement techniques (i.e., surveying, photogrammetry, remote sensing, electromagnetic spectroscopy, etc.) and comprehensive analysis (structural health monitoring analysis, operational modal analysis) must be performed (Tobiasz et al., 2019). It is important to consider (1) factors that can influence the degradation of the objects and (2) appropriate inventory methods when it comes to establishing the conservation schedule.

The documentation in the form of the point clouds, 3D models, images and vector drawings are an essential and irreplaceable part of the preservation of cultural heritage sites and should be further promoted among researchers (Stylianidis, 2019). To perform the architectural documentation and visualisation of cultural objects and sites, close-range photogrammetric methods based on the active (range-based) and passive (image-based) methods are used (Abbate et al., 2019; Arif and Essa, 2017; Cipriani et al., 2019; Grussenmeyer and Yasmine, 2004; Hatzopoulos et al., 2017; Heras et al., 2019; Kot et al., 2020; Markiewicz et al., 2020, 2017; Remondino and El-Hakim, 2006). Selection of the appropriate method for 3D shape reconstruction and structural health monitoring depends on many factors and requirements of the final documentation, namely: resolution, quality, accuracy, level of detail and complexity of the developed object (Gonizzi Barsanti et al., 2013).

\section{DEVELOPED METHODOLOGY}

The surface of the chapel dome was measured in July 2017 using laser scanning technique. The scan was performed with $\mathrm{Z}+\mathrm{F} 5006 \mathrm{~h}$ scanner from the scaffolding level, ensuring accuracy within $0.5 \mathrm{~mm}$. The measurement was made in the "super high" resolution, which provides the distance between the observed points on average of approximate $1.0 \mathrm{~mm}$ depending on the target distance and the angle of incidence of the laser beam. The full resolution point cloud consists of 96 715492 points (Fig. 3a), which results in a spatial resolution of approx. 194 points per 1 square centimetre. The scans were preprocessed and registered in the $\mathrm{Z}+\mathrm{F}$ LaserControl software. The scanned data and collected photos were used to develop a high-resolution 3D model of the chapel dome.

In addition, the image-based method was used to obtain a 3D model of the chapel architecture. It was performed using a Canon 5D camera equipped with a lens of $14 \mathrm{~mm}$. The images were also taken from the scaffolding level. The spatial model was obtained in the Regard 3D program. The surface of the painting was analysed in lateral and UV light. This method enabled identifying some traces of the original drawings and determining the range of over-paintings and retouches. The cleaning tests of the painting decoration from dust, old putties and ancient interventions was executed in the chapel dome. The probes and cleaning tests carried out on the lantern vault and walls showed the presence of the previously unknown polychrome. The original 18th-century painting was discovered on the vault under the secondary layer of burned, lime white and plaster layers. The painting covered with soot due to fire was probably painted over in the XIX-th century. Until now, it was completely unknown. The mortar and painting layers samples were taken for the chemical analysis to recognise the technique and technology of Żebrowski's wall paintings.

In 2018, the photogrammetric photos after cleaning the painting surface were taken by the company $4 \mathrm{~K}$ Damian Kwiecien. A 3D model of the chapel dome was obtained by Structure-fromMotion/Multiview Stereo approach using a Canon EOS 5D SR camera equipped with a $24 \mathrm{~mm}$ lens EF F1.4 L USM. Flashing lights Quantuum Quadralite Pulse 800 Pro (temperature of light $5600 \mathrm{~K}$ ) were used. The 3D model of the chapel dome was generated in the Agisoft Metashape software. The colour scale X-Rite Colour Checker Classic was applied.

In 2019 and 2020, the panoramic images of the dome paintings after retouching and reconstruction works were repeated by the company 4K Damian Kwiecień A 3D.

Rescue and conservation work of the mural painting in the chapel had a wide range namely, reinforcement of the building's structure elements, aesthetic solutions concerning the arrangement of rococo painting decoration. The appearance of the dome was changed significantly because of the undertaken work. In 2019, the photos after conservation were taken by the company 4K Damian Kwiecień. Due to financial restrictions, the creation of the 3D model of the dome was abandoned, only a panoramic unwrapping of the painting composition after conservation and restoration works was made.

Data from two different sources were used for this research: TLS scans obtained in 2017 and digital images from 2018. Data processing can be divided into three main parts. 1) Data registration to get two registered point clouds, 2) Registration of these clouds with each other, and 3) Data comparison.

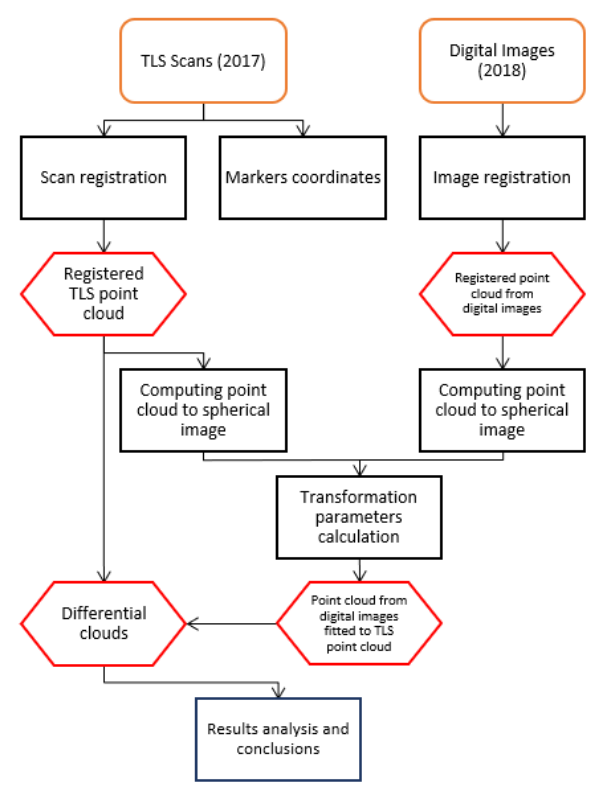

Figure 1: The schematic of the performed investigation. 


\subsection{TLS data pre-processing}

Before processing the TLS data, it was decided to automatically filter the point clouds based on the analysis of the laser beam intensity (too low and too high removed) and by removing isolated points (filter out points from the data set whose nearest neighbour (point) has a distance greater than the $10 \mathrm{~cm}$ ). This was followed by manual filtering of areas that were not of interest. Such areas included the scaffolding and the lantern located on the upper ring of the dome. The result of the filtering is shown in Figure 2 .

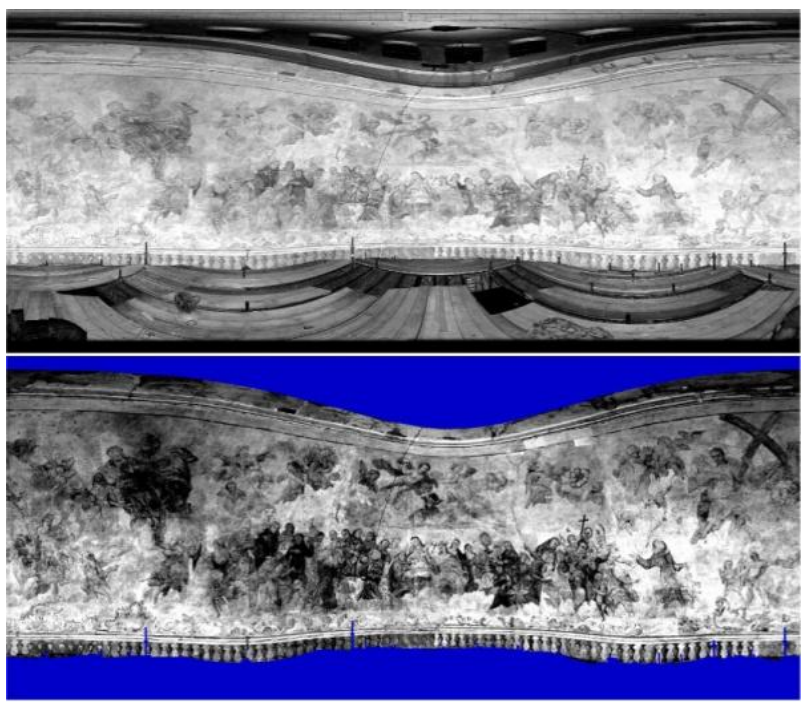

Figure 2: Spherical image of the dome before filtration (top image) and after filtration (bottom image).

The next step was to relatively register the filtered scans from the two TLS positions. Placing targets on tripods and walls of the measured object was not possible due to potential damages to the measured object. Therefore, it was decided to use natural points. Finding such points was not a problem in the case of an object of this type, i.e., richly decorated and with numerous details. In the process of registration of TLS scans SIFT algorithm was used. The algorithm was applied to spherical images of the scans (Fig. 3). Coordinates of the keypoints in the pixel coordinate system were calculated to XYZ coordinates. A transformation was performed based on the coordinates of identical points (assumed as tie points) in both point clouds, taking one of the scans as reference data. The whole process was iterative. Incorrect points were removed from equations until achieving a defined threshold (Markiewicz and Zawieska, 2019). The results of the registration are shown in Table 1 .

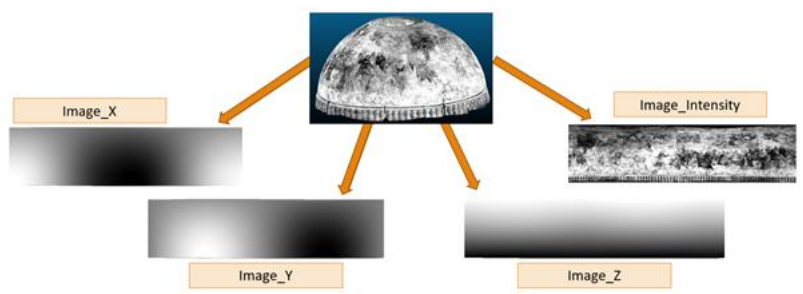

Figure 3: Diagram presenting the generation of spherical images from the TLS point cloud.

\subsection{Image data pre-processing}

A process of image orientation was performed in the Agisoft Metashape software. To generate the dense point clouds, 175 images were taken using lenses with different focal lengths. The images were divided into 15 groups related to the selected lens to carry out the self-calibration process. To enchase imagematching, several points (markers) were selected manually. For those markers, 3D coordinates were assigned from registered scans. This allowed for a rough registration of dense point clouds with TLS scans. The rough image's orientation results are shown in Table 1.

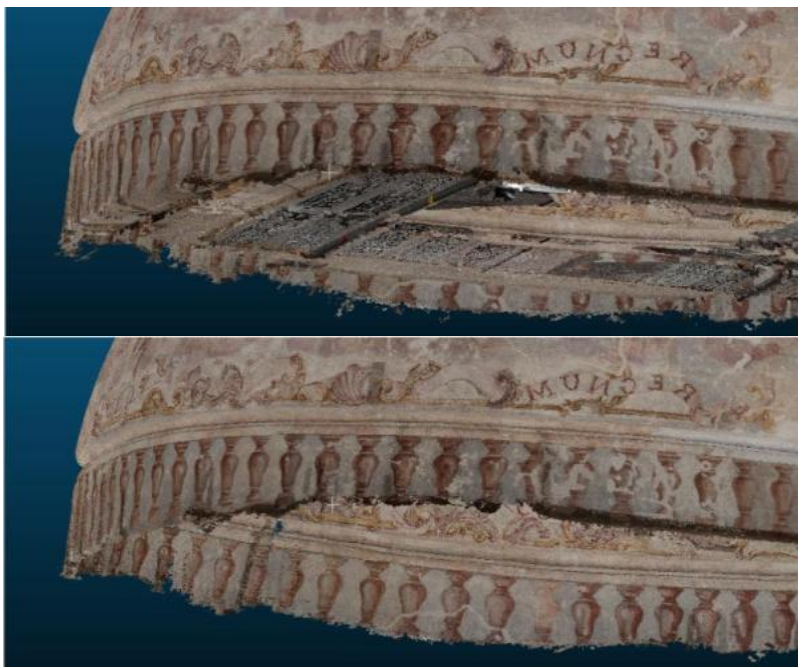

Figure 4: The result of the MVS point cloud filtration.

Like the point clouds acquired from Terrestrial Laser Scanning, the point cloud was filtered automatically. For these purposes, the Statistical Outlier Removal (SOR) (Point Cloud Library, 2021) algorithm was utilised (Fig. 4). Only solid fragments of scaffolding were removed manually.

\subsection{Point clouds data co-registration}

After filtering point clouds, co-registration of two data sets was carried out. Both point clouds were transferred into orthoimage, based on cartography and map projections methods. For every point, new XY coordinates were calculated. Coordinate Z stands for point attributes, e.g., RGB components or original coordinates $\mathrm{X}, \mathrm{Y}$ and $\mathrm{Z}$ (Fig. 3). From those new point clouds, rasters were generated.

The previously mentioned SIFT algorithm was used to find keypoints between RGB orthoimage from 2018 and intensity orthoimage from 2017. The example of tie points on TLS and RGB spherical images is shown in Figure 5.

Next, based on $\mathrm{X}, \mathrm{Y}$ and $\mathrm{Z}$ rasters, coordinates in both point clouds coordinate system were interpolated (Fig.3). Finally, having XYZ values of keypoints, it was possible to calculate transformation parameters for one of the point clouds (Fig. 5). The results of the point cloud registration are shown in Table 1.

\begin{tabular}{|c|c|c|c|c|}
\hline & \multicolumn{2}{|c|}{$\begin{array}{l}\text { TLS data pre- } \\
\text { processing }\end{array}$} & \multirow{2}{*}{$\begin{array}{l}\text { Image data } \\
\text { pre- } \\
\text { processing }\end{array}$} & \multirow{2}{*}{$\begin{array}{l}\text { Data co- } \\
\text { registration }\end{array}$} \\
\hline & $\begin{array}{c}\text { Before } \\
\text { filtration }\end{array}$ & $\begin{array}{c}\text { Final } \\
\text { adjustment }\end{array}$ & & \\
\hline $\begin{array}{l}\text { No. of } \\
\text { points }\end{array}$ & 10839 & 9668 & $\begin{array}{c}40604 \\
215\end{array}$ & 782 \\
\hline $\mathrm{V}_{\mathrm{X}}[\mathrm{cm}]$ & 9.8 & 0.1 & 0.4 & 0.2 \\
\hline $\mathrm{V}_{\mathrm{Y}}[\mathrm{cm}]$ & 8.2 & 0.2 & 0.6 & 0.2 \\
\hline $\mathrm{V}_{\mathrm{Z}}[\mathrm{cm}]$ & 2.9 & 0.1 & 0.3 & 0.2 \\
\hline$\sigma$ & 7.6 & 0.1 & 0.8 & 0.3 \\
\hline
\end{tabular}

Table 1. Results of the data registration 


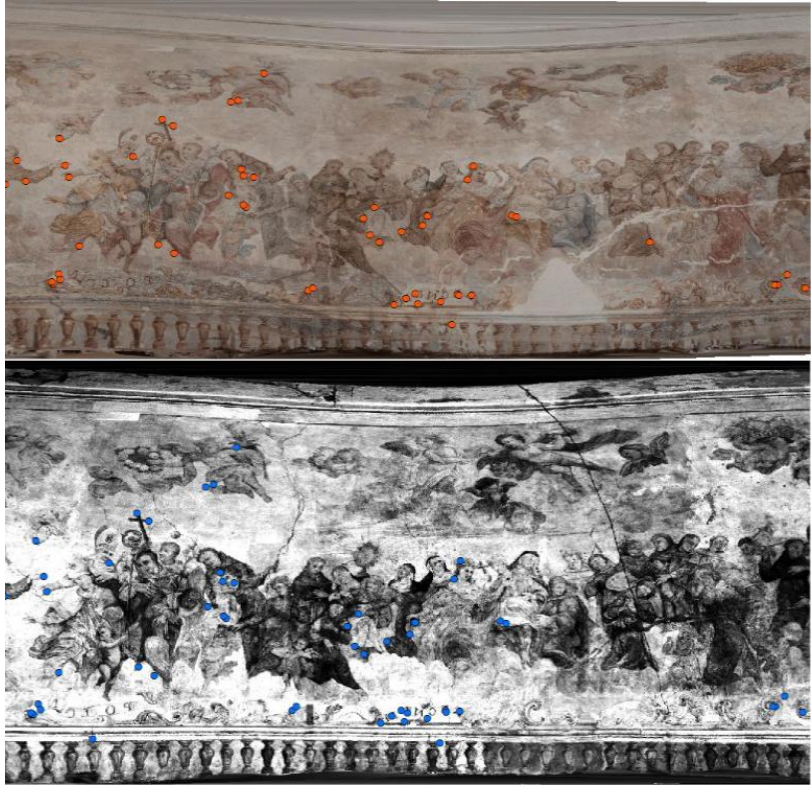

Figure 5:The example of the corresponding points distribution on the fragment of the spherical images.

\section{RESULTS}

The correlation of data on the state of preservation of the dome paintings (obtained with laser measurements, photogrammetric representations, and digital photography) was extremely important during the conservation works. Laser measurement of the dome surface before conservation, combined with the 3D model obtained by photogrammetry, enabled a global analysis of the state of preservation of the paintings and detailed identification of the most endangered fragments of the polychrome. Based on the measurements, the preservation of the original layer was estimated as $96 \%$ plasters and $63 \%$ paints. The 3D model obtained based on the scan was correlated with digital photos of the areas before conservation. In this way, the sections of mortar loss, the detachment sites of the bottom plaster layer from the brick support, and shallower delamination between the plasters were inventoried. Thanks to the scanning of the dome surface, the depth and precise course of the cracks were recognised. The scope of past interventions and restorations was also estimated. Mapping of the state of preservation of the dome paintings in the digital photos, correlated with the 3D model of the dome, allowed to capture certain regularities concerning the processes and causes of damage (Fig. 6 and 7). An analysis of the shape of the mortar cracks showed that the horizontal structural fracture of the dome wall in the northern part, located at approximately $1 / 3$ of the way up, divides the dome into two separate working parts, one of which tends to slide with the slope movement. At the same time, the other is associated with the main nave of the church. The parallel crack lines observed on the W-E axis confirmed the existing stress directions. The radially arranged cracks along the base of the lantern indicated a disturbance of the stability of its base - the stone cornice. Analysing the geometry and profiles of the dome walls also allowed us to assess the aesthetics of plaster and stucco repairs made during previous interventions. It turned out that some of them have a significantly different nature from the surface of the original parts (they are too high, too smooth, or too coarse and grainy). The dome paintings were redocumented after the technical conservation works were completed. Then, a model of the 3D dome was created using photogrammetric methods. Thanks to the implemented solutions, it was possible to compile both measurements (before conservation and after technical work), which allowed for a detailed analysis of the results. The scope and quality of the treatments were analysed for how the new fillings and putties coincided with the previously diagnosed areas of loss and damage (Fig. 6 and 7). Their profiles and texture were assessed in detail, and, on this basis, local, precise corrections were executed.
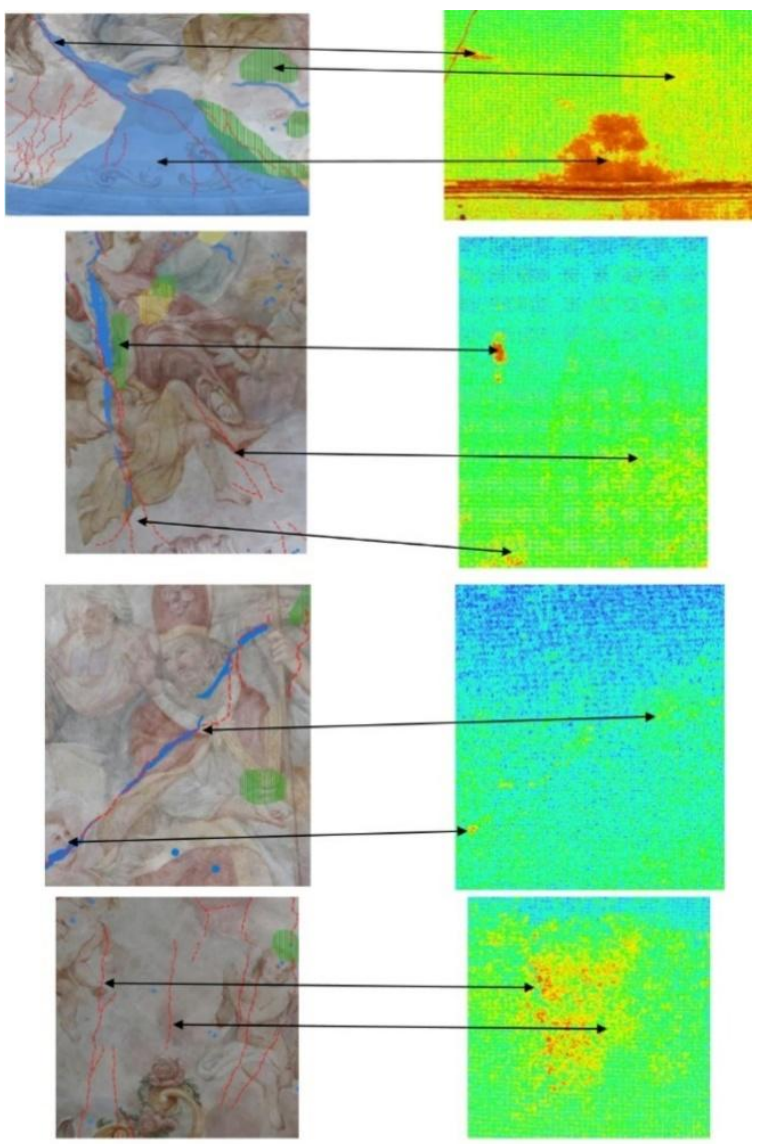

Deviations $[\mathrm{cm}]$ 77.8

0.0

(a)

(b)

Figure 7: Comparison of the damage map from classical conservation works (a) and deviations maps acquired from differential point clouds

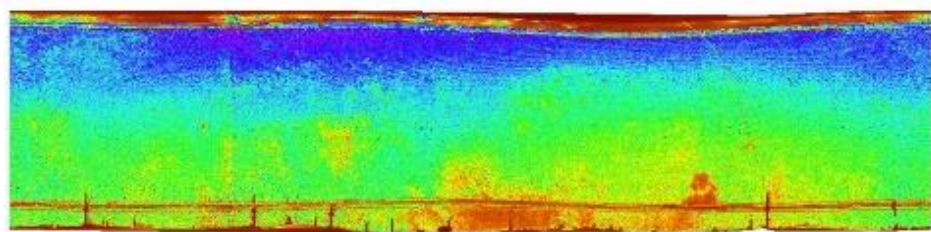

Deviations $[\mathrm{cm}]$

Figure 6: The deviation map acquired from differential point clouds. 
In conserving and restoring wall paintings, it is also important to understand their meanings and the context of their origins. Baroque painting is a carrier of historical, religious, and symbolic content. Hence, the correct interpretation of particular scenes is crucial for conservation work. The iconography, composition, and colours of Walenty Żebrowski's paintings were strongly deformed due to layers of dirt, damp, and the previous consolidation and repainting treatments. Reading the meaning of the complex scene depicted in the chapel's dome caused serious interpretative problems. Therefore, panoramic expansions of the entire scene in the form of a horizontal strip proved to be very helpful. During the work, the following materials were used:

- laser scan of the painting surface before conservation works (July 2018)

- photogrammetric representation of the paintings after cleaning and removing of the old repairs and repainting (September 2018)

- panoramic representation of the paintings during restoration works (September 2019, September 2020).

Based on panoramic photos of the entire scene juxtaposed with precise images of its fragments and an analysis of the preserved relics, supported by art historical research, it was possible to read the meaning of the paintings in the dome and to recognise particular saints and their attributes (Fig. 9).

Having registered point clouds with each other, it is possible to analyse changes that occurred during conservation work. Calculated distances between both point clouds show the localisation of cracks and damages on the dome wall. Along with that, the size and depth of crevices can be measured. Acquired distance point cloud also was transferred into orthoimage. For improved readability of the location of the damages final raster was vectorised, filtered out of the noise. Vector layer was applied to the orthoimage from images. Polygons represent places where the distance between both point clouds is greater than $2.8 \mathrm{~mm}$. To verify the results vector layer was compared with a damage map of the dome, developed by the conservation team using traditional methods (Fig. 8).

\section{CONCLUSIONS}

The Rescue Project was undertaken in the Blessed Ladislas' chapel in St. Anna's Church in Warsaw, Poland. The main goal of the planned work was to restore the original rococo character of the dome paintings. The aim of this article was to present the integration of the multi-temporal conservation works and noninvasive measurements for changes analysis during conservation work. For this purpose, a method based on comparing point clouds from terrestrial laser scanning and the SfM/MVS method was proposed.

The obtained results were not ideal, and only the biggest damages were presented. Smaller cracks were not detected or only detected in some parts.

One of the elements that had a negative influence on results was data which originally was obtained with a view of the presentation of the general geometry of the dome and its paintings. The methods that were used allow this. However, information on cracks smaller than $3 \mathrm{~mm}$ could not be acquired. To overcome this, the images should have a larger overlap. Also, an issue with unequal distribution of light on photos was observed. This could also have an impact on the quality of the final products. In the case of the scans, more scanner positions should be used, with intend of having most of the wall scanned from the closest distance possible.

Another problem that occurred was the lack of the use of targets. This forced usage of the characteristic points in the process of scans and images registration. Applied here SIFT algorithm is in itself very accurate. However, this method causes a risk of a situation where both point clouds from different years are registered better in places where damages were repaired. Because of this, damages in those places are not detected. No damage detection in the upper part of the dome suggests the occurrence of this phenomenon. Because of the object's historical character, placing targets on the wall is impossible. This could cause further damage to the paint layer. Therefore, registration of the point clouds should be based on keypoints located in non-damaged places. This requires close cooperation of a photogrammetric with a conservator, who can point out wall fragments where geometry is unchanged.

Despite these issues, it has been concluded that photogrammetric methods can detect and measure microdamages. This includes integrated data from different sources. Identified crevices had depth above $3 \mathrm{~mm}$. The application of mentioned improvements could increase the effectiveness and accuracy of damage detection and allow for the representation of even smaller cracks in the wall. The quality of the products can also be improved by cooperating with photogrammetric and conservator during the stage of manual filtration of results.
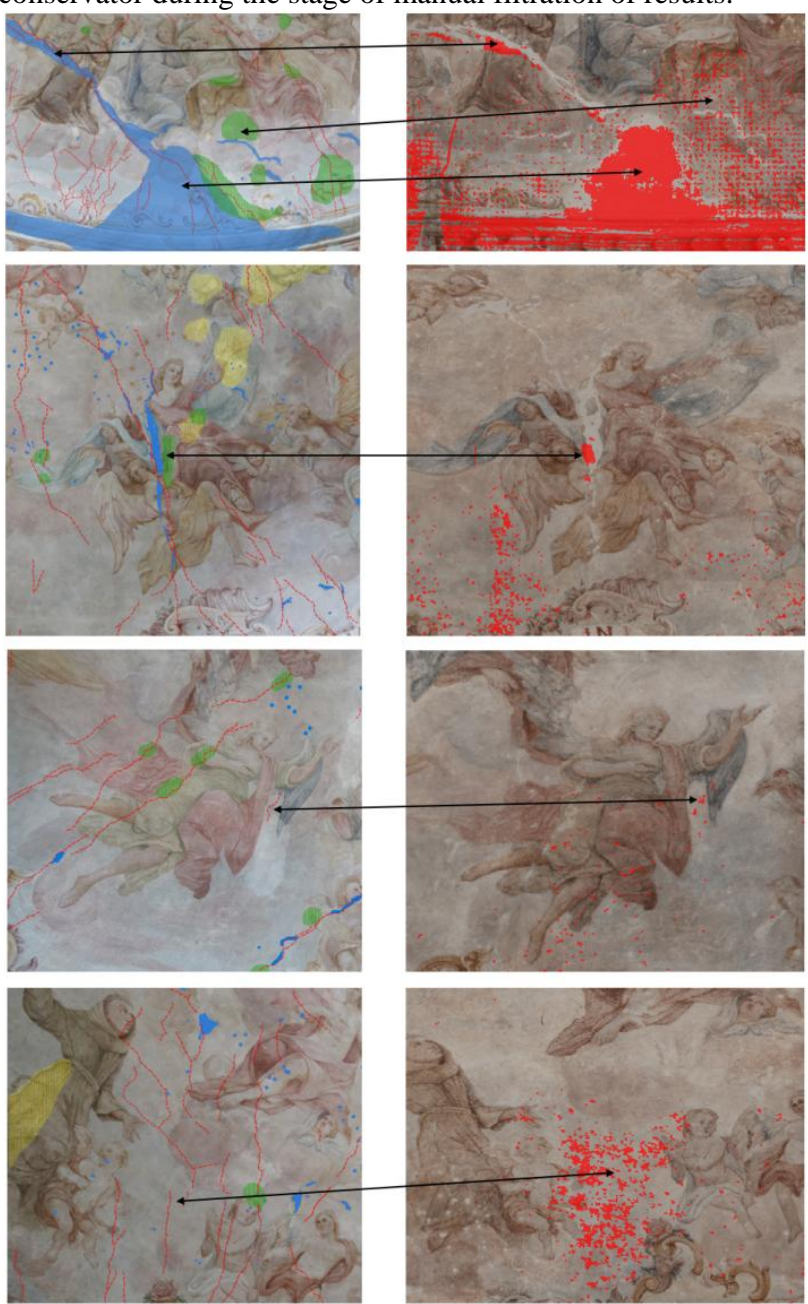

(a)

(b)

Figure 8: Comparison of the damage map (a) and vector layer acquired from differential point clouds (b). 

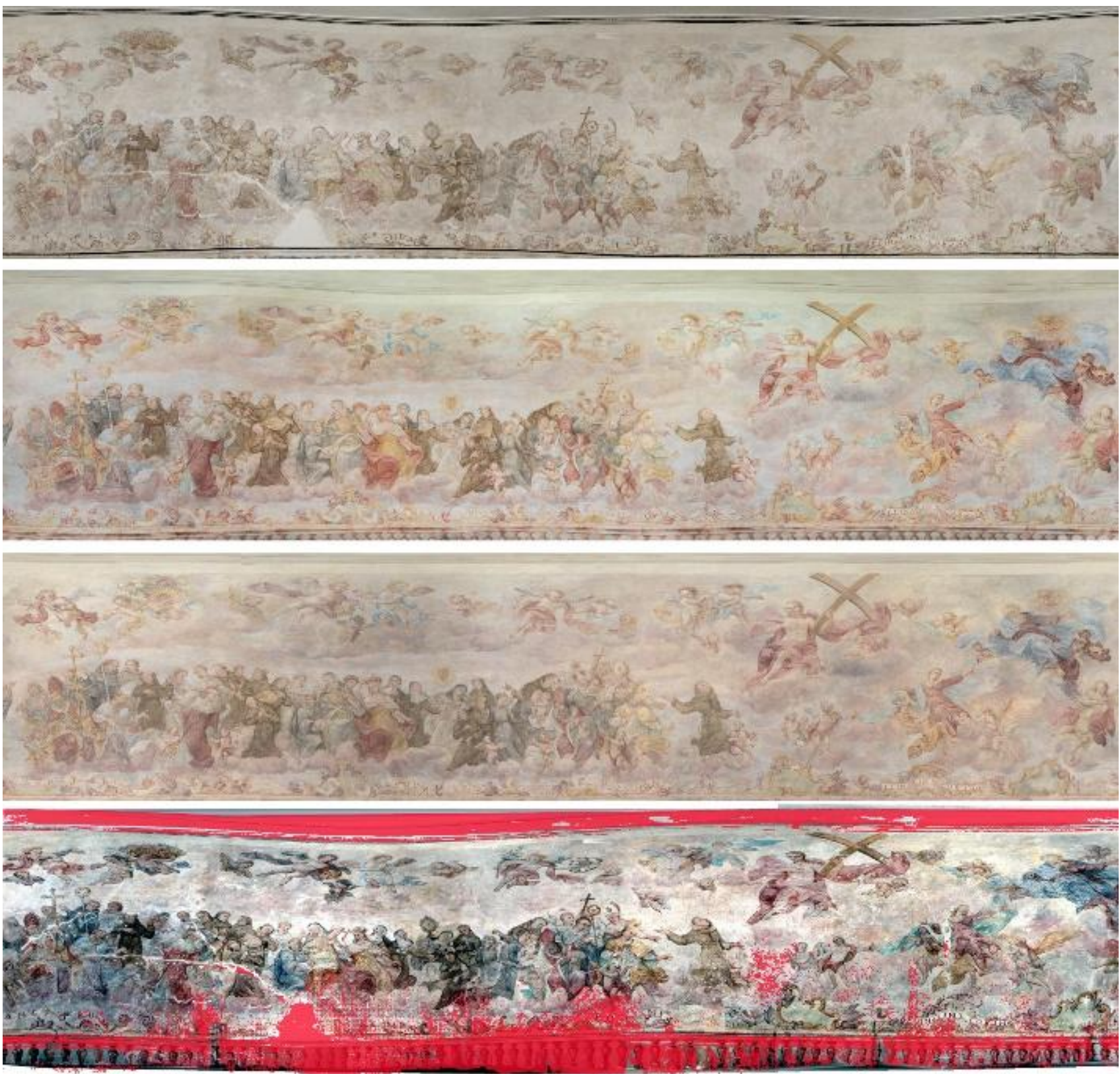

Figure 9: Multitemporal panoramas(before, during and after conservation works) with the map of automated detected areas for conservation works (red areas).

\section{ACKNOWLEDGEMENT}

In 2017, the Rescue Project leaded by Katarzyna Górecka, Maria Pokorna-Paruszkiewicz and Rafał Nijak was undertaken in the Blessed Ladislas' chapel in St. Anna's Church in Warsaw (Poland).

\section{REFERENCES}

Abbate, E., Sammartano, G., Spanò, A., 2019. Prospective upon multi-source urban scale data for 3D documentation and monitoring of urban legacies. ISPRS - Int. Arch. Photogramm. Remote Sens. Spat. Inf. Sci. XLII-2/W11, 11-19. https://doi.org/10.5194/isprs-archives-XLII-2W11-11-2019

Arif, R., Essa, K., 2017. Evolving techniques of documentation of a world heritage site in Lahore. ISPRS - Int. Arch. Photogramm. Remote Sens. Spat. Inf. Sci. XLII-2/W5, 33-40. https://doi.org/10.5194/isprs-archives-XLII-2-

\section{W5-33-2017}

Cipriani, L., Bertacchi, S., Bertacchi, G., 2019. An optimised workflow for the interactive experience with cultural heritage through reality-based 3D models: Cases study in archaeological and urban complexes. ISPRS - Int. Arch. Photogramm. Remote Sens. Spat. Inf. Sci. XLII-2/W11, 427-434. https://doi.org/10.5194/isprs-archives-XLII-2W11-427-2019

Clim, D.-A., Groll, L., Diaconu, L.-I., 2017. Moisture - the Main Cause of the Degradation of Historic Buildings. Bul. Institutului Politeh. Din Iaşi 63, 65-78.

Gonizzi Barsanti, S., Remondino, F., Visintini, D., 2013. 3D surveying and modeling of archaeological sites \&ndash; Some critical issues \&ndash; Some, in: ISPRS Annals of the Photogrammetry, Remote Sensing and Spatial Information Sciences. https://doi.org/10.5194/ 
isprsannals-II-5-W1-145-2013

Grussenmeyer, P., Yasmine, J., 2004. Photogrammetry for the Preparation of Archaeological Excavation. A 3D Restitution According to Modern and Archive Images of Beaufort Castle landscape (Lebanon). Int. Arch. Photogramm. Remote Sens.

Hatzopoulos, J.N., Stefanakis, D., Georgopoulos, A., Tapinaki, S., Pantelis, V., Liritzis, I., 2017. Use of various surveying technologies to $3 \mathrm{D}$ digital mapping and modelling of cultural heritage structures for maintenance and restoration purposes: The Tholos in Delphi, Greece. Mediterr. Archaeol. Archaeom. 17, 311-336. https://doi.org/10.5281/zenodo.1048937

Heras, V., Sinchi, E., Briones, J., Lupercio, L., 2019. Urban heritage monitoring, using image processing techniques and data collection with terrestrial laser scanner (TLS), case study cuenca-Ecuador. ISPRS Ann. Photogramm. Remote Sens. Spat. Inf. Sci. 42, 609-613. https://doi.org/10.5194/isprs-Archives-XLII-2-W11-6092019

ICOMOS, 2003. ICOMOS (2003) - ICOMOS Charter. Princ. Anal. Conserv. Struct. Restor. Archit. Herit. 3-6.

Kot, P., Markiewicz, J., Muradov, M., Lapinski, S., Shaw, A., Zawieska, D., Tobiasz, A., Al-Shamma'A, A., 2020. Combination of the photogrammetric and microwave remote sensing for Cultural Heritage documentation and preservation - preliminary results. Int. Arch. Photogramm. Remote Sens. Spat. Inf. Sci. - ISPRS Arch. 43, 1409-1413. https://doi.org/10.5194/isprs-archivesXLIII-B2-2020-1409-2020

Markiewicz, J., Łapiński, S., Kot, P., Tobiasz, A., Muradov, M., Nikel, J., Shaw, A., Al-Shamma'a, A., 2020. The quality assessment of different geolocalisation methods for a sensor system to monitor structural health of monumental objects. Sensors (Switzerland) 20, 1-39. https://doi.org/10.3390/s20102915

Markiewicz, J., Zawieska, D., 2019. The Influence of the Cartographic Transformation of TLS Data on the Quality of the Automatic Registration. Appl. Sci. 9, 509. https://doi.org/10.3390/app9030509

Markiewicz, J., Zawieska, D., Podlasiak, P., 2017. Comparing multi-source photogrammetric data during the examination of verticality in a Monumental tower. Int. Arch. Photogramm. Remote Sens. Spat. Inf. Sci. - ISPRS Arch. 42, 475-480. https://doi.org/10.5194/isprsarchives-XLII-2-W3-475-2017

Point Cloud Library, 2021. Statistical Outlier Removal filter [WWW Document]. URL https://pcl.readthedocs.io/projects/tutorials/en/latest/statis tical_outlier.html

Remondino, F., El-Hakim, S., 2006. Image-based 3D Modelling: A Review. Photogramm. Rec. 21, 269-291. https://doi.org/10.1111/j.1477-9730.2006.00383.x

Stylianidis, E., 2019. CIPA - Heritage Documentation: 50 Years: Looking Backwards. ISPRS - Int. Arch. Photogramm. Remote Sens. Spat. Inf. Sci. XLII-2/W14, 1-130. https://doi.org/10.5194/isprs-archives-XLII-2W14-1-2019

Tobiasz, Markiewicz, Łapiński, Nikel, Kot, Muradov, 2019. Review of Methods for Documentation, Management, and Sustainability of Cultural Heritage. Case Study: Museum of King Jan III's Palace at Wilanów. Sustainability $\quad 11$, 7046. https://doi.org/10.3390/su11247046 